\title{
Increased Vascular Endothelial Growth Factor (VEGF) Expression in Wistar Rat Oral Mucosa Traumatic Ulcer due to Golden Sea Cucumber (Stichopus hermanni) Extract Gel
}

\author{
Pratiwi Soesilawati, Eghia Laditra Ambarani, Yuliati and Aqsa Sjuhada Oki \\ Department of Oral Biology, Faculty of Dental Medicine, Universitas Airlangga, Surabaya, Indonesia
}

\begin{abstract}
Background. Traumatic ulcer is a lesion formed by a local tissue damage due to trauma on epithelial layer. Vascular Endothelial Growth Factor (VEGF) plays an important role in wound healing, especially in angiogenesis. Golden sea cucumber (Stichopus hermanni) is believed to accelerate the wound healing process.

Objective. To prove that golden sea cucumber extract can increase VEGF expression in oral mucous membrane traumatic ulcer in rat.

Method. S. hermanni extract was prepared by freeze-dry method, then an extract was made using PEG 400 or PEG 4000 at $40 \%$ and $80 \%$ concentrations, respectively, and applied to the animal's oral wounds. The animals were divided into three groups: control; $40 \%$ S. hermanni extract gel; and $80 \% \mathrm{~S}$. hermanni extract gel. The ulcers that formed on day 3 were rubbed gently with S. hermanni extract gel. After being sacrificed on day 4, sample tissues from the lower lips were prepared for histopathology to count the number of VEGF expression. The results were analyzed using the One-Way ANOVA statistical test.
\end{abstract}

Results. A significant increase in the VEGF expression of $80 \%$ concentration $S$. hermanni extract gel was found compared with those in the control group $(p=0.00)$.

Conclusion. Golden sea cucumber extract (Stichopus hermanni) gel increased the VEGF expression in oral mucous traumatic ulcer.

Key Words: Sticophus hermanni, oral mucous traumatic ulcer, VEGF, healing

\section{INTRODUCTION}

Paper presented at the Joint Scientific Meeting in Special Care Dentistry, July 5, 2019, Amerta Room, 4th Floor, main campus of Universitas Airlangga, Surabaya, Indonesia.

Corresponding author: Pratiwi Soesilawati

Department of Oral Biology

Faculty of Dental Medicine

Universitas Airlangga

J. Mayjen. Prof. Dr. Moestopo No. 47 Surabaya 60132 - Indonesia

Email: pratiwi-s@fkg.unair.ac.id
Ulcer is a lesion on the epithelial layer with boundaries creating shallow round and one of the most common cause is trauma. The most common types of ulcer are traumatic ulcer and Stomatitis Aphthosa Recurrent (SAR). ${ }^{1,2}$ The estimated point prevalence of oral ulcers worldwide is $4 \% .{ }^{3}$ Wound healing process consists of early phase (inflammation), intermediate phase (proliferation), and advanced phase (maturation). Each phase has different biological process and different role of cells. Angiogenesis process is an important part of wound healing and stimulated by different cytokines and growth factors including the vascular endothelial growth factor (VEGF) which acts as a potent angiogenic factor. VEGF is produced by keratinocyte, macrophage, and fibroblasts during wound healing. Macrophage also has an 
important role in the wound healing process, and it secretes different kinds of growth factors and cytokines, especially on the third and fourth days from the time the wound starts. The growth factors attract cells which play a role in the proliferation process into the area of the wound. $4,5,6$

In the event of an injury, therapy is needed to help in the wound healing process. In general, people use povidone iodine as a therapy in wounds. Povidone iodine alone has side effects at a certain concentration. $10 \%$ povidone iodine has a tendency to irritate and may cause skin damage, as well as cause allergies or toxic effects to sensitive people. ${ }^{7}$ Povidone iodine with concentrations greater than $3 \%$ can also give a sense of heat to the skin, and it is also quite expensive.

Treatment of wounds using natural ingredients has been done, among others, using plants and animals that are effective to help the wound healing process. In Chinese and Malaysian literatures, sea cucumbers have been known as tonics and traditional remedies that are effective for cuts and burns. Sea cucumbers, therefore, have the potential to be commercialized in modern medicine. ${ }^{8,9}$

Sea cucumbers contain $86.8 \%$ protein, $80 \%$ collagen, minerals, mucopolysaccharide, glycosaminoglycans (GAG), chondroitin, omega 3, omega 6, omega 9, and amino acids. The saponins in sea cucumbers are antioxidants and natural antiseptics. Collagen, mucopolysaccharide and amino acid of Stichopus variegatus serve as growth factor. ${ }^{10}$ Studies show that glycosaminoglycan (GAG) sulfates such as chondroitin sulfate and heparan sulfate may have positive effects in wound healing. ${ }^{11}$

In the wound healing process, VEGF has a role that stimulates release of von Willebrand factor from endothelial cells and induces the activity of tissue expression factor in endothelial cells and monocytes. VEGF also plays an important role in inducing angiogenesis as well as enhanced microvascular permeability. ${ }^{12}$ Therefore, the following research was undertaken to study the effects of golden sea cucumber extract on VEGF expression in induced oral traumatic ulcer.

\section{METHODS}

This study was an experimental research, with randomized posttest-only control group design. It was conducted at the Department of Biochemistry Faculty of Medicine, Airlangga University and Department of Biochemistry and Biomolecular Faculty of Medicine, Brawijaya University.

Golden sea cucumber (Stichopus hermanni) was prepared by washing and separation from the internal organ. The rest of the tissues were dried on blotting paper, then homogenized. Every fifty (50) grams of homogenized tissue were placed in a $250 \mathrm{~mL}$ conical flask. $100 \mathrm{~mL}$ water was added to each flask. The mixture was shaken using a water-bath shaker at $80 \mathrm{rev} / \mathrm{min}$ at room temperature for 4 hours. The mixture was centrifuged at 3,000 rpm for 20 minutes. The extracts were freeze-dried using a freeze-dryer (Heto model FD3, ID 87164) producing powdered sea cucumber. These were stored in sterile bottles at $4^{\circ} \mathrm{C}$. From the 800 gram freezefried stock, $15 \mathrm{gram}$ of fresh sea cucumber extract was obtained. The extracts were made into gel using PEG 400 and PEG 4000 (NT-Itrade, Jiangsu, China) at 40\% and 80\% concentrations, respectively.

The sample in this study was male Rattus norvegicus Wistar strain laboratory rats, 200-300 grams body weight and aged between 8-16 weeks old, healthy physical condition and no abnormalities in the oral mucosa. Eighteen rats were divided into three groups, namely: Group I (control group); Group II (40\% golden sea cucumber extract); Group III (80\% golden sea cucumber extract).

To create the traumatic ulcer, the animals were administered inhalation anesthetics using 10\% ether, then the bottom lip mucosa was smeared with $0.12 \%$ Chlorhexidine digluconate, injured with burnisher no. 4, heated for 1 minute and touched for 1 second to create a $2 \mathrm{~mm}$-wide traumatic ulcer wound. On day 3 after the wounds were made, the $40 \%$ and $80 \%$ golden sea cucumber extract gels were applied to the traumatic wound in Groups II and III, respectively.

The animals were sacrificed using lethal dose of ether. The mucosa of the lower lip was excised up to the corner of the mouth, including the ulcerated part. The tissues were preserved in a $10 \%$ buffered formalin $(\mathrm{pH} 7.4)$. The fixation in buffered formalin was repeated twice with fresh solution. The tissues were rinsed, dehydrated in graded alcohol, cleared in xylene, and finally embedded in paraffin and cut at $5 \mu \mathrm{m}$ thickness.

The tissues were stained using immunohistochemical techniques of biotin streptavidin to detect VEGF expression. The examination was carried under a light microscope 400 times magnification. Positive cells gave a blackish brown color among bluish or greenish negative cells. Each preparation was observed in 4 viewing fields in clockwise directions at 3 , 6, 9 and 12. The data were analyzed using One-Way ANOVA and Tukey HSD (Honestly Significant Difference) test to know the differences among treatment and control groups.

\section{RESULTS}

The results of VEGF expression is shown in Table 1. From these data, it can be concluded that VEGF expression in histological preparation of the lower lip mucosa of Wistar rat traumatic ulcers was found to be highest in the $80 \%$ group, while the lowest was the control group (Figure 1).

One-Way ANOVA test showed significant differences $(p=0.000)$, which was subsequently analyzed with Tukey HSD test.

Tukey HSD test results showed that there was no significant difference between the $40 \%$ group and control group, whereas the $80 \%$ concentration group was significantly higher compared to the control group. 

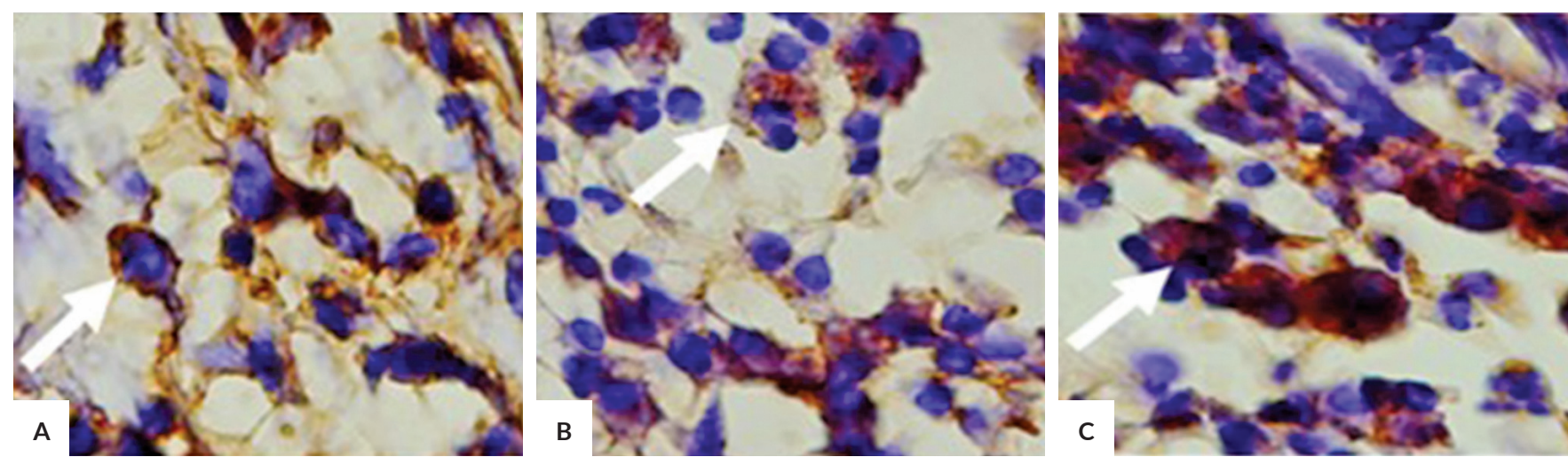

Figure 1. Histological image of VEGF expression of traumatic ulcer in the oral cavity of male wistar rat with immunohistochemical staining at 400x magnification. (A) Group control; (B) Treatment group with 40\% sea cucumber extract gel; (C) Treatment group with $80 \%$ sea cucumber extract gel. Image shows increased VEGF expression in the treatment group compared to the control group.

Table 1. The result of different test of VEGF expression

\begin{tabular}{lrc}
\multicolumn{1}{c}{ Group } & \multicolumn{1}{c}{ X \pm SD } & p \\
I. Control & $4,16 \pm 0.98^{\mathrm{a}}$ & 0.000 \\
II. 40\% Concentration & $6,16 \pm 1.47^{\mathrm{a}}$ & 0.000 \\
III. 80\% Concentration & $14,83 \pm 2.31^{\mathrm{b}}$ & 0.000 \\
\hline
\end{tabular}

Note: Superscripts $a$ and $b$ show significant differences by Tukey HSD test

\section{DISCUSSION}

The mean result of VEGF expression on histological preparation in control group has the lowest mean compared to the treatment groups. Table 1 shows $80 \%$ concentration of sea cucumber extract increased VEGF expression $(p=0.000)$ on wound healing compared to the control group. In the $40 \%$ group, golden sea cucumber extract did not show significant difference compared to control group ( $p=0.1333$ ). This proves that sea cucumber extract could accelerate the wound healing process.

Glycosaminoglycan is a long chain compound composed of replicated disaccharide units having carboxyl groups and one or more sulfates, one of which is $\mathrm{N}$-acetylgalactosamine or $\mathrm{N}$-acetylglucosamine. Examples of GAG sulfates are chondroitin sulfate, dermatan sulphate, sulfate filtration, heparan sulfate, and heparin. ${ }^{13}$ Protein embodied in golden cucumber include glycine, arginine amyl glutamate. ${ }^{9}$

In the process of angiogenesis, chondroitin sulfate and dermatan sulphate stimulate macrophages to produce nitric oxide (NO). ${ }^{14}$ Nitric oxide functions as a medium in a variety of physiological and pathological functions, including angiogenesis and vascular permeability. ${ }^{15}$ Nitric oxide can increase VEGF expression through hypoxiainducible regulation factor $1 \alpha(\mathrm{HIF}-1 \alpha) .{ }^{16}$ When the wound healing process occurs, the high consumption of oxygen by active macrophages leads to decreased oxygen levels resulting in hypoxia. The state of hypoxia causes an increase in HIF$1 \alpha$ in the trauma area. Oxygen is key in the generation of metabolic energy in all eukaryotic cells. Decrease of the oxygen supply to the tissues are common physiological and pathophysiological events. Fluctuations in the supply of oxygen (hypoxia) make cells have a compensatory mechanism when hypoxia occurs. One of the mechanisms is hypoxia-inducible factor (HIF), a transcription factor that serves as a mechanism of adaptation to hypoxia. ${ }^{17}$

$\mathrm{HIF}$ is a heterodimer protein consisting of alpha subunits and beta subunits. HIF regulates various genes, many of which have important roles in the wound healing process. HIF signaling allows the tissues to adapt and protects inflammatory hypoxia. HIF also regulates gene expression that triggers angiogenesis. ${ }^{17} \mathrm{HIF}-1 \alpha$ is a cell response regulator at the time of hypoxia that can increase the expression of some of the genes involved in the adaptation process due to decreased oxygen. The alpha subunit is regulated or influenced by oxygen. The alpha sub-unit is degraded during normoxia (normal oxygen concentration) via a proteasome-dependent pathway mechanism after hydroxylation of two proline residues by the alpha sub-unit i.e. prolyl-hydroxylases (PHDs). In the event of hypoxia, the PHDs are inhibited, the HIF-1 $\alpha$ subunit accumulates and is immersed with HIF-1 $\beta$. That process stimulates the expression of the HIF target gene. The target gene of HIF is the various genes in the proteins involved in angiogenesis and wound healing processes such as VEGF and erythropoietin (EPO). ${ }^{18}$

In the event of hypoxia, the activity of PHDs is reduced due to the limited oxygen. This results in a change in HIF-1 $\alpha$ stabilization in the cell cytoplasm and translocation to the nucleus. This change causes dimerization with HIF-1 $\beta$ units. The dimerization forms the transcriptional function of the HIF-1 $\beta$ dimer, which later binds to cis-acting hypoxia response elements (HREs) in the target gene promoter, such as EPO and VEGF. When dimerization occurs, HIF- $1 \alpha$ and HIF- $1 \beta$ bind to HREs which increases the expression of VEGF. The result of this cascade, the 
sequence of transcription of the target HIF gene to the mRNA increases. However, the stabilization of HIF- $1 \alpha$ is a gradual process and is assessed from mild to chronic hypoxic progression. ${ }^{17}$

In addition, one of the contents of the golden sea cucumber extract that affects the increase in VEGF expression is arginine. Intercellular $\mathrm{L}$-arginine is a material for synthesis of $\mathrm{NO}$, but $\mathrm{NO}$ production also requires L-arginine derived from extracellular, although it has sufficient intercellular L-arginine concentrations. ${ }^{19}$ The content of arginine contained in the golden sea cucumber extract is expected to increase NO production that will stimulate the increase of VEGF expression.

\section{CONCLUSION}

The results indicated that $80 \%$ golden sea cucumber extract (Stichopus hermanni) gel increased VEGF expression in oral mucous traumatic ulcer.

\section{Statement of Authorship}

All authors participated in data collection and analysis, and approved the final version submitted.

\section{Author Disclosure}

All authors declared no conflict of interest.

\section{Funding Source}

The study was financially supported by Faculty of Dental Medicine, Universitas Airlangga, Surabaya, Indonesia by Lecturer-Students Research Grant.

\section{REFERENCES}

1. Regezi JA, Sciubba JJ, Jordan RCK. Oral pathology: Clinical pathologic correlations, 5th ed. New York: Elsevier; 2008. pp. 22-3.

2. Long M. Mouth Ulcer [Internet]. 2008 [cited 2015 May]. Available from www.betterhealth.vic.gov.au.

3. Patil S, Doni B, Wadhawan R, Maheshwari S, Santosh B, Khandelwal S. Prevalence of benign oral ulcerations in the Indian population. Journal of Cranio-Maxillary Diseases. 2014; 3(1):26.

4. Cebeci ARI, Gulsahi A, Kamburoglu K, Orhan BK, Oztas B. Prevalence and distribution of oral mucosal lesions in an adult Turkish population. Med Oral Patol Oral Cir Bucal. 2009; 14(6): E272-7.
5. Lawrence WT. Wound Healing Biology and Its Application to Wound Management. Dalam: O'Leary JP, Tabuenca A. The Physiologic Basis of Surgery, Ed 4. Philadelphia: Lippincott Williams \& Wilkins; 2008. pp. 150-175.

6. Rosenberg L., de la Torre J. Wound Healing, Growth Factors. Emedicine.com. 2006.

7. Larson EL. APIC Guidelines Committee. APIC guideline for handwashing and hand antisepsis in health care settings. Washington, DC: The Association for Professionals in Infection Control and Epidemiology, Inc.; 1995.

8. Jeong I, Park S, Jeong JS, Kim DS, Choi YS, Lee YS, et al. Comparison of catheter-associated urinary tract infection rates by perineal care agents in intensive care units. Asian Nurs Res (Korean Soc Nurs Sci). 2010; 4(3):142-50. doi: 10.1016/S1976-1317(10)60014-X.

9. Bordbar S, Anwar F, Saari N. High-value components and bioactives from sea cucumbers for functional foods-a review. Mar Drugs. 2011; 9(10):1761-1805. doi: 10.3390/md9101761.

10. Ibrahim NI, Wong SK, Mohamed IN, Mohamed N, Chin KY, ImaNirwana S, Shuid AN. Wound healing properties of selected natural products. Int J Environ Res Public Health. 2018; 15(11). pii: E2360.

11. Masre SF, Yip GW, Sirajudeen KNS, Ghazali FC. Wound healing activity of total sulfated glycosaminoglycan (GAG) from Stichopus vastus and Stichopus hermanni integumental tissue in rats. International Journal of Molecular Medicine and Advance Sciences. 2010; 6(4):49-53.

12. Matsumoto T, Claesson-Welsh L. VEGF receptor signal transduction. Sci STKE. 2001; 2001(112):re21.

13. Kimata K, Habuchi O, Habuchi H, Watanabe H. Knockout mice and proteoglycan. In: Kamerling JP, et al (eds). Comprehensive glycoscience, vol 3, Chap 4.10. Amsterdam: Elsevier. 2007; pp. 159-191.

14. Wrenshall L E, Stevens RB, Cerra B, Platt JL. Modulation of macrophage and B cell function by glycosaminoglycans. J Leukoc Biol. 1999; 66(3):391-400.

15. Frank $\mathrm{S}$, Kämpfer $\mathrm{H}$, Wetzler $\mathrm{C}$, Pfeilschifter J. Nitric oxide drives skin repair: Novel functions of an established mediator. Kidney Int. 2002; 61(3):882-8.

16. Kuwabara M, Kakinuma Y, Ando M, Katare RG, Yamasaki F, Doi $Y$, et al. Nitric oxide stimulates vascular endothelial growth factor production in cardiomyocytes involved in angiogenesis. J Physiol Sci. 2006; 56(1):95-101.

17. Goggins BJ, Chaney C, Radford-Smith GL, Horvat JC, Keely S. Hypoxia and integrin-mediated epithelial restitution during mucosal inflammation. Front Immunol. 2013; 4:272. doi: 10.3389/ fimmu.2013.00272.

18. Conde E, Alegre L, Blanco-Sánchez I, Sáenz-Morales D, AguadoFraile E, Ponte B, et al. Hypoxia Inducible Factor 1-Alpha (HIF1 Alpha) is induced during reperfusion after renal ischemia and is critical for proximal tubule cell survival. PLoS One. 2012; 7(3):e33258. doi:10.1371/journal.pone.0033258

19. Wyatt AW, Steinert JR, Mann GE. Modulation of the L-arginine/ nitric oxide signalling pathway in vascular endothelial cells. Biochem Soc Symp 2004; (71):143-56. 